\title{
VALOR SOCIAL DEL DESARROLLO DE LA AUTOESTIMA EN ESTUDIANTES DEL BACHILLERATO DE LOS SECTORES POPULARES
}

\author{
SELF-ESTEEM POSITIVE IN HIGH SCHOOL STUDENTS OF THE POPULAR \\ SECTORS
}

\section{RESUMEN}

Este artículo busca caracterizar la autoestima en adolescentes analizándolo desde el proceso formativo escolar, donde la figura del docente es fundamental para su desarrollo .Se enfatiza en la necesidad de desarrollar una autoestima positiva sobre todo en estudiantes vulnerables de sectores populares con un nivel alto de pobreza y con una serie de problemas sociales que se orientan a un desempeño académico poco favorable como consecuencia del desarrollo de autoestima negativa. Todo este estudio surge de la identificación de algunas falencias detectadas al interior de establecimientos educativos con las características antes mencionadas.

PALABRAS CLAVES: vulnerables, autoestima,pobreza, proceso formativo

\begin{abstract}
This magazine article look for to explore self-esteem in adolescents analyzing it from the school learning process where the figure of the teacher is critical to their development. Emphasis is placed on the need to develop positive self especially popular sectors vulnerable students with a high level of poverty and with a number of social problems that focus on unfavorable academic performance. All this study arises from the identification of some shortcomings detected within educational institutions sectors. KEY WORDS: vulnerable, self-esteem, poverty, educational process
\end{abstract}

\section{INTRODUCCIÓN}

Indiscutiblemente que uno de los elementos más significativos para alcanzar el éxito en los estudiantes es desarrollar en ellos una autoestima positiva, es decir, saberse y sentirse 
competente en diferentes aspectos. Cuando un estudiante fracasa en un área específica del rendimiento escolar disminuye y su autoestima será amenazada;en cambio cuando tiene éxito, se siente aprobado, aceptado y valorizado; los sentimientos asociados a esas situaciones de éxito van a ir modificando positivamente las percepciones que el joven tiene de sí mismo. Esta situación se hace más notoria en estudiantes de sectores populares, sujeto de este estudio, jóvenes del bachilleratoen edad comprendida entre 15 a 18 años, con índices de pobreza bastante altos, a quienes las condiciones sociales y culturales afectan de forma directa el desarrollo de su personalidad, ya que el entorno sociocultural adverso donde se forman, le proporcionan riesgos, por lo que es muy común observar en los estudiantes de establecimientos con estas características bajos niveles de autoestima que inciden directamente en su proceso de formación.

Considerando la importancia de que un estudiante desarrolle una autoestima positiva para garantizar de alguna manera el éxito en su proceso formativo se ha realizado este estudioque tiene como objetivo caracterizar la autoestima en los estudiantes del bachillerato de la Unidad educativa Simón Bolívar del cantón Portoviejo, provincia de Manabí, institución ubicada en un sector urbano marginal de la ciudad de Portoviejo.

La observación participante y la experiencia de la autora de esta investigación con 28 años en la docencia en establecimientos educativos de sectores populares han sido claves para determinar que la autoestima, a pesar de ser un aspecto relevante para el desarrollo del adolescente, no es abordada con la asertividad requerida tanto por docentes como por los consejeros estudiantiles que no han asumido su verdadero rol frente a esta problemática, en muchos casos por la falta de preparación de los involucrados en el tratamiento de la autoestima, aun estando consientes de la necesidad de desarrollarla para superar problemas de desempeño escolar y comportamiento en el aula.

En el caso de estudiantes de establecimientos de sectores populares la situación es más preocupante, ya que la mayoría de ellos presentan síntomas de autoestima negativa, lo que conlleva a problemas académicos y comportamentales. Lacomunidad y, en algunos casos, los profesores no tienen mayores expectativas de estosestudiantes, provocando la estigmatización de los establecimientos objeto de esta investigación. Muchos de los comentarios de personas ajenas a este tipo de establecimientos apuntan a tratar a estos estudiantes como "delincuentes", "chicos sin futuro" o"drogadictos", lo que en ningún caso resulta una ayuda para los adolescentes. Es en estosestablecimientos donde se necesitan proyectos educativos integrales, tendientes a mejorar la autoestima de este grupo de jóvenes. 


\section{MATERIALES Y MÉTODOS}

Los métodos utilizados para el presente estudio son los teóricos: como el analítico y sintético, utilizado para el tratamiento y discernimiento de la información, los estadísticos para el manejo de datos cuantitativos relacionados con el desempeño de los estudiantes y la información obtenida en la investigación de campo aplicada en la Unidad Educativa Simón Bolívar. Dentro de las técnicas constan: la entrevista, aplicada a los tutores y miembros del departamento de Consejería estudiantil, encuesta a los docentes de la misma institución, con la finalidad de conocer el tratamiento de la autoestima en el proceso formativo escolar; el análisis documental,requerido para revisar el resultado de la autoevaluación institucionalen lo que tiene que ver al desempeño de los estudiantes en los últimos cinco años y el completamiento de frases, así como la técnica de los diez deseos, para conocer el nivel de autoestima de los estudiantes de la institución objeto de esta investigación.

\section{DESARROLLO}

La ley Orgánica de Educación intercultural en el literal w del artículo 2 en cuanto a los principios de la educación menciona a la calidad y calidez en el proceso formativo del niño y adolescente como condiciones fundamentales para su desarrollo integral, el mismo que manifiesta que se debe promover condiciones adecuadas de respeto, tolerancia y afecto que generen un clima escolar propicio para el aprendizaje, condiciones muy favorables que desde el proceso formativo se debe propiciar para desarrollar en los estudiantes una autoestima positiva que fortalezca la personalidad del escolar adolescente, sobre todo considerando a los jóvenes de los sectores populares que es donde elautoestima negativa se pone de manifiesto con mayor intensidad.

Para esta investigación se realizó un diagnóstico fáctico, análisis de los antecedentes en el estudio de la temática y la observación participante de la autora con 28 años de experiencia en la docencia de instituciones de sectores populares, lo que permitió detectar las siguientes insuficiencias:

a.- Dificultades por parte de los docentes para la dirección del proceso enseñanza aprendizaje en los estudiantes del bachillerato.

b, Medio social que influye negativamente y no propicia el desarrollo de la autoestima positiva.

c.- Estudiantes manifiestan agresividad e irrespeto

d.-Dificultad en el manejo de las relaciones interpersonales entre los estudiantes.

e.- Desmotivación de los estudiantes en el orden académico. 
Carl Rogers máximo exponente de la psicología humanista expresa que la génesis de los problemas de muchas personas está en que se consideran seres indignos y sin valor, por lo que el concepto de autoestima se aborda desde la escuela humanista, sintetizado en el siguiente axioma: "Todo ser humano sin excepción por el mero hecho de serlo, es digno de respeto incondicional de los demás y de sí mismo; merece estimarse a sí mismo y que se lo estime"

El concepto de autoestima varía en función del paradigma psicológico que lo aborde (psicología humanista, psicoanálisis, o conductismo). Desde el punto de vista del psicoanálisis, la autoestima está íntimamente relacionada con el desarrollo del ego; por otro lado, el conductismo se centra en conceptos tales como "estímulo"“respuesta", "refuerzo"“aprendizaje". La autoestima es además un concepto que ha traspasado frecuentemente el ámbito exclusivamente científico para formar parte del lenguaje popular. El budismo considera al ego una ilusión de la mente, de tal modo que la autoestima, e incluso el alma, son también ilusiones; el amor y la compasión hacia todos los seres con sentimientos y la nula consideración del ego, constituyen la base de la felicidad absoluta. Para el Budismo, "no hay un camino hacia la felicidad, la felicidad es el camino"

Ante lo antes expuesto se puede apreciar que son muchos los autores que han definido a la autoestimay todos coinciden en que esta es la percepción valorativa que tenemos de nosotros mismos, de nuestra manera de ser, de quienes somos, el conjunto de rasgos corporales mentales y espirituales que configuran la propia personalidad;

La autora de este artículo coincide con la definición de la ecuatorianaVillegas Isabel,(2012) quien en su investigación sostiene que: ' 'la autoestima constituye el núcleo básico de nuestra identidad y corresponde a una actitud hacia uno mismo generada por la integración de otros'”. Esta definición admite una intervención del contexto en la formación de una autoestima positiva o negativa, dependiendo de las condiciones en que ese contexto haya influenciado al individuo y que está estrechamente ligado con la formación de su personalidad.

Se hace necesario para este estudio realizar una caracterización de las clases de autoestima Autoestima Positiva

(Magendzo, 1997: 95) señala que la autoestima positiva es el núcleo de una personalidad sana y que es la responsable de la felicidad personal y la convivencia social.Esta clase de autoestima está fundamentada de acuerdo a los sentimientos de la persona con sí misma: 
la capacidad y el valor. Los individuos con una autoestima positiva poseen un conjunto de características internas e interpersonales que los hace enfrentarse de manera positiva a los retos que deba enfrentar. Tienden a adoptar una actitud de respeto no sólo con ellos mismos sino con el resto. Por otro lado, en un sujeto con una autoestima alta existen menos probabilidades de autocrítica, en relación con las personas que poseen otro tipo de autoestima.

\section{La autoestima yel proceso de formación escolar}

Hoy por hoy el proceso formativo escolar requiere moldear un tipo de persona que sepa desenvolverse en el plano personal intelectual, moral y social. Esto quiere decir que el estudiante que se está formando sea coherente con una persona integral, democrática, respetuosa de su género, por supuesto, una persona con autoestima positiva.

La pobreza en la niñez es el predictor más consistente de problemas en el desarrollo y en el rendimiento escolar, debido a las condiciones de vida ligadas a la falta de recursos; es uno de los factores de riesgo que más influye en la vulnerabilidad de las personas. Los efectos acumulados de la pobreza aumentan la vulnerabilidad física y psicosocial del niño que crece y se desarrolla en un ambiente deprivado (UNESCO-UNICEF 1996 UNESCO 1997)La educación y la autoestima son aspectos muy relacionados, sobre todo cuando el escenario son sectores populares ubicados en lugares urbanos marginales donde las condiciones socioculturales soninfraestimulantes y decisivas en el desarrollo de una autoestima positiva, y es que la autoestima tiene que ver con el rendimiento escolar, con la motivación, con el desarrollo de la personalidad, con las relaciones sociales y con el contacto afectivo del estudiante consigo mismo. Cada vez que se establece una relación, se está trasmitiendo aprobación o desaprobación y en esa misma medida, se van devolviendo o entregando características personales que pasan a integrar la autoimagen de esa persona.

El rol del docente es significativo al momento de desarrollar una autoestima positiva en estudiantes de sectores populares, ya que estepuede influir positiva o negativamente en su autoestima, considerando que los estudiantes de este grupo viven en condiciones muy especiales, rodeados de drogadicción, prostitución, alcoholismo violencia intrafamiliar, situaciones que perturban su existencia y los hacen presa fácil de desarrollar una autoestima negativa desencadenante de múltiples factores que atentan contra el desarrollo de su personalidad y la dificultad para lograr sus metas, ya que la interacción con el profesor va teniendo repercusiones en el sentimiento de confianza de sí mismo. 
Se puede apreciar que existe una relación circular; si el adolescente tiene una autoestima positiva se comportará en forma agradable, será cooperador, responsable, rendirá mejor, manejará buenas relaciones interpersonales, lo que facilitará el trabajo escolar, por lo que se requiere de un docente positivo reforzante, estimulante que entregará retroalimentación positiva, muy preocupado por los ingentes problemas que pude tener un estudiante de sectores populares con toda su carga social; lo que hará que el estudiante tenga un comportamiento armónico, generándose un círculo virtuoso.

Si su autoestima es baja o negativa se pondrá agresivo irritable, poco cooperador, poco responsable. Con esta situación es altamente probable que el profesor tienda a asumir una postura más crítica y rechazante frente al joven, quien a su vez, se pondrá más negativo y desafiante, creándose así un círculo vicioso.

Por otro lado, se ha encontrado una relación entre la autoestima de los profesores y la autoestima de los niños. Los profesores con una buena autoestima son más reforzadores, dan más seguridad a los niños, están más satisfechos con su rendimiento escolar, desarrollan un clima emocional más positivo y sus alumnos se aprecian más contentos en la sala de clases.

Los profesores con baja autoestima tienden a tener miedo de perder autoridad, por lo tanto usan una disciplina mucho más represiva y sus alumnos son menos creativos, no saben trabajar solos, son más tensos e irritables y dependen del control que el adulto ejerce sobre ellos.

Haeussler y Milicia (1994: 30) manifiestan que hay una relación entre un positivonivel de autoestima y un concepto académico adecuado de sí mismo. Un joven con ambos ámbitos en un buen nivel se caracteriza por:

- Orientarse hacia el logro de las tareas planteadas en el proceso de enseñanza aprendizaje.

- Tener una baja ansiedad frente a los desafíos.

- Mantener la probabilidad de éxito a pesar de los problemas.

- Obtener un alto rendimiento académico.

Por el contrario, el adolescente que posee una baja autoestima y un concepto

Académico desmejorado, se ve incapaz de afrontar los desafíos escolares, es rechazado y que los demás también lo aíslen.

\section{Dimensiones de la autoestima}

Muchos autores coinciden en que la autoestima está dividida en dimensiones

Que son muy significativas dentro de la edad escolar.

\section{DIMENSIÓN FÍSICA}


Se refiere en ambos sexos, al hecho de sentirse atractivo físicamente. Incluye también, en los adolescentes, el sentirse fuerte y capaz de defenderse; y en las niñas, el sentirse armoniosa y coordinada, bonita.

\section{Dimensión social}

Incluye el sentimiento de sentirse aceptado o rechazado por sus compañerosy el sentimiento de pertenencia, es decir el sentirse parte de un grupo. También se relaciona con el hecho de sentirse capaz de enfrentar con éxito diferentes situaciones sociales; por ejemplo, ser capaz de tomar la iniciativa, ser capaz de relacionarse con personas del sexo opuesto y solucionar conflictos interpersonales con facilidad. Finalmente, también incluye el sentido de solidaridad.

\section{Dimensión afectiva}

Está muy relacionada con la anterior, y tiene mucho que ver la familia, se refiere a la autopercepción de características de personalidad, como sentirse:

- Simpático o antipático

- Estable o inestable

- Valiente o temeroso

- Tranquilo o inquieto

- De buen o mal carácter

- Generoso o tacaño

- Equilibrado o desequilibrado

\section{Dimensión académica}

Se refiere a la autopercepción de la capacidad para enfrentar con éxito las situaciones de la vida escolar y específicamente a la capacidad de rendir bien y ajustarse a las exigencias escolares.

Incluye también la autovaloración de las capacidades intelectuales, como sentirse inteligente, creativo y constante, desde el punto de vista intelectual

\section{Dimensión ética}

Se relaciona con el hecho de sentirse una persona buena y confiable o, por el contrario, mala y poco confiable. También incluye atributos como sentirse responsable o irresponsable, trabajador o flojo. La dimensión ética depende de la forma en que el niño interioriza los valores y las normas, y de cómo se ha sentido frente a los adultos cuando las ha transgredido o ha sido sancionado. Si se ha sentido cuestionado en su identidad cuando ha actuado mal, su autoestima se verá distorsionada en el aspecto ético

\section{DISCUSIÓN}


De lo descrito anteriormente, se desprende que la autoestima juega un papel trascendente en el proceso de enseñanza aprendizaje sobre todo de los estudiantes de sectores populares, ya que el medio donde se desarrolla este grupo es infraestimulante para el desarrollo de un autoestima negativa, de ahí la importancia que tiene el proceso formativo en la personalidad del joven, por lo que es importante que el estudiante esté motivadotanto por su entorno familiar como social y la relación docente-alumno es fundamental,ya que el medio donde el estudiante adquiere sus conocimientos debe ser armónico, ameno, agradable, participativo, lo que conlleva a un eficaz proceso de enseñanza aprendizaje . Es fundamental que tanto la familia como el proceso formativo tengan como prioridad crear en el joven una autoestima positiva que los motive a adquirir conocimientos, valores que lo lleven a desempeñarse como un individuo útil e integral para la sociedad por consiguiente se debe seguir estudiando elperfil de autoestima de estos educandos para mejorar el proceso de enseñanza aprendizaje.

\section{CONCLUSIONES}

1.-El concepto de autoestima debe ser abordado desde un enfoque humanista como lo plantea Carl Rogers.

2.-El proceso formativo escolar debe moldear al individuo, buscando la formación integral del joven.

3.- Los estudiantes de los sectores populares son muy vulnerables a desarrollar autoestima negativa dada a las condiciones adversas de su entorno sociocultural.

4- Estudiantes con baja autoestima se sienten desvalorizados y presentan bajos desempeños académicos.

5.- El rol del docente es muy significativo al momento d desarrollar una autoestima positiva en estudiantes de sectores populares ya que tiene la oportunidad de incidir positiva o negativamente en la formación de su personalidad.

6.- La característica principal de un profesor con baja autoestima es tener miedo a perder autoridad.

\section{BIBLIOGRAFÍA}

Acaro Sarango, N. (2010) la autoestima como potenciadora del desarrollo integral de la niñez y la adolescencia en las instituciones de la región sur del Ecuador.

Alvarez Delgado, G.S. (2007). Autoestima en los alumnos de los liceos con alto índice de vulnerabilidad escolar.

Ley Orgánica de Educación Intercultural

Branden, N. (2010), El poder de la autoestima. 
PerezHell, E Y.(2010). La educación de la capacidad de organización de la vida en la atención a estudiantes de desventaja social desde la prevención educativa.

Schwartz Doris (1998), La autoestima y su importancia.

\section{Datos del autor:}

Lic. Leonor Bravo Vélez Mg. Sc.

Universidad Estatal del Sur de Manabí

Ecuador 